\title{
Multidimensional assessment of caregiver burden in home-based nursing: a cross-sectional study
}

Ang Yi Han ${ }^{1}$, Muhd Nurhasanuddin Abdullah Kelali², Hanif Abdul Rahman ${ }^{1}$

${ }^{1}$ PAPRSB Institute of Health Science, Universiti Brunei Darussalam; ${ }^{2}$ Geriatric and Palliative Department RIPAS Hospital, Brunei Darussalam

Received: October 29, 2019

Accepted: January 20, 2020

\section{Correspondence}

Hanif Abdul Rahman

PAPRSB Institute of Health Sciences, Universiti

Brunei Darussalam, Tungku Link Road, BE1410,

Brunei Darussalam

E-mail: hanif.rahman@ubd.edu.bn

\section{Conflict of interest}

The Authors declare no conflict of interest

How to cite this article: $Y i$ Han $A, A b-$ dullah Kelali MN, Rahman HA. Multidimensional assessment of caregiver burden in home-based nursing: a cross-sectional study. Journal of Gerontology and Geriatrics 2020;68:146-51. https://doi. org/10.36150/2499-6564-403

C Copyright by Società Italiana di Gerontologia e Geriatria (SIGG)

\section{(c) (1) () $\Theta$}

\section{OPEN ACCESS}

This is an open access article distributed in accordance with the CC-BY-NC-ND (Creative Commons Attribution-NonCommercial-NoDerivatives 4.0 International) license. The article can be used by giving appropriate credit and mentioning the license, but only for non-commercial purposes and only in the original version. For further information: https://creativecommons.org/licenses/by-nc-nd/4.0/deed.en
Background. Caregivers experience a number of challenges when caring for a chronically ill patient which can affect their physical, emotional and psychological health.

Aim. To assess caregiver burden and its relationship to health-related quality of life among primary caregivers of patients with long-term illness in the community.

Methods. A cross-sectional study using caregiver burden scale and SF-36 Survey on thirty-two caregivers of patients with long-term illness under a community health centre in Brunei from January to March 2019. Findings. Caregiver burden was highest for general strain, isolation and disappointment. Increased age of caregiver was significantly associated with reduced physical functioning. Male caregivers had significantly higher role functioning while female caregivers had significantly higher social functioning role. Increased caregiver burden showed decreased overall health-related quality of life.

Conclusions. Caregiver burden should not be disregarded in patient treatment plan. Clinicians and relevant authorities should collaborate care plans with primary caregivers accounting for both patient and caregiver well-being. More detailed qualitative studies should be done to provide a better insight on caregiver burden.

Key words: caregiver burden, community, chronic patients, cross-sectional study, quality of life

\section{INTRODUCTION}

Primary caregivers of chronically ill patients who are mainly consist family members or relatives, face a lot of challenges when providing care to these patients, and this could put varying amount of strain on the caregiver in multiple aspects ${ }^{1}$. According to Zarit and colleagues, caregiver burden can be defined as "the extent to which caregivers perceived their emotional or physical health, social life, and financial status as suffering as a result of caring for their relative" ${ }^{2}$. The act of caregiving refers to the activities involved in providing assistance to the care receivers who are unable to carry out these activities by themselves ${ }^{3}$.

Caregiver burden can have numerous impacts on the caregiver. In terms of social relationships, the caregiver will be more distant with his/her other family members and friends as they devote more of their time to physical tasks related to caregiving ${ }^{1}$. The physical health of caregiver can also be compromised as they can get injured easily while performing caregiving 
tasks and often disregard their own health ${ }^{1}$. It can also take a financial toll on the caregiver especially if the caregiver is taking care of a patient with chronic neurological disease; the total annual cost for caring people with dementia, Parkinson's disease and multiple sclerosis in the U.S. are $\$ 100$ billion, \$ 23 billion, and $\$ 450$ million respectively ${ }^{1}$. Emotionally, the caregivers can succumb to negative emotions such as anger, depression, regret, and others ${ }^{1}$.

Cognitive disability in patients with Parkinson Disease and dementia significantly increases caregiver burden and decreases the quality of life even when mild levels of cognitive deficiency are present ${ }^{4}$. However, caregiver burden is often disregarded by clinicians ${ }^{5}$. This is important because if the clinician does not address the burden shouldered by the caregiver, it can become overwhelming, physically and emotionally challenging, and isolating ${ }^{1}$. Caregiver burden could be classified into two categories which are objective burden $(\mathrm{OB})$ and subjective burden (SB). OB is the physical activities that caregivers are required to perform and it is also referred to the harmful effects of the disease on the caregivers ${ }^{6}$. $\mathrm{SB}$ is the result of objective burden which affects the caregivers psychologically, socially and emotionally ${ }^{\text {? }}$.

This was the first study that evaluated caregiver burden in the community of Brunei Darussalam. The findings will be useful for the clinicians as it allows them to not only focus on the patients receiving the care but also the caregivers themselves. By identifying the issue, caregiver burden can be reduced by providing suitable support and advice.

\section{METHODS}

\section{STUDY AIMS}

The aim of this study is twofold:

1 to describe prevalence of 5 factors of caregiver burden (general strain, isolation, disappointment, emotional involvement and environment) among primary caregivers of patients in the community;

2 to investigate the relationship between caregiver burden and health-related quality of life.

\section{StUdy DESIGN AND POPULATION SELECTION}

This was a cross-sectional study using interviewerassisted administration of questionnaire that was conducted in January 2019 to March 2019. The target population was all the caregivers of home-based patients under one of the main primary healthcare centres in Brunei. Eligibility criteria included primary caregivers of home-based patients with any long-term condition (e.g. dementia and stroke).

\section{RESEARCH INSTRUMENTS}

The English version of the self-administered questionnaire was divided into 3 sections. The first section consists of sociodemographic information which includes age, gender, individual income, ethnicity, religion, number of years of formal education, and kinship. The second section includes 22 questions based on the caregiver burden (CB) scale that assess 5 factors of caregiver burden subjectively which comprise of general strain, isolation, disappointment, emotional involvement and environment ${ }^{8}$. General strain is the amount of pressure that the participant experiences as a result of physical workload, isolation refers to the decrease in contact with family or friends as a result of carrying out activities related to caregiving, disappointment is the feeling of unfairness regarding the participant's own life, emotional involvement refers to the negative feelings that the participant may have towards the care recipient such as anger and embarrassment, and environment refers to environmental factors that may affect the participant's ability to perform their duties ${ }^{8}$.

The third section contains questions related to the health-related quality of life which were developed by RAND ("Research and Development") Corporation. According to the scoring instructions provided by RAND Corporation, this 36-Item Short Form Survey contains 36 items that are related to 8 health concepts which include physical functioning, bodily pain, role limitations due to physical health problems (physical role functioning), role limitations due to emotional problems (emotional role functioning), emotional well-being, social functioning, energy/fatigue, and general health perceptions. Physical functioning is the ability to perform physical activities such as bathing and dressing, bodily pain is the amount of pain that the participant experiences, role limitations due to physical health problems refer to the absence or presence of issues with daily activities due to physical health, role limitations due to emotional problems refers to the presence or absence of issues with daily activities due to emotional problems, emotional well-being is the mental state experienced by the participant such as happiness or depression, social functioning refers to the participant's ability to participate in social events, and general health perceptions are the participant's thoughts on their own health ${ }^{9}$.

\section{Statistical ANALYSIS}

Collected data were entered and analysed using RStudio Desktop version 1.1.463 (for Windows). The descriptive statistical analyses were conducted for caregivers' sociodemographic characteristics including estimation with 95\% confidence intervals (Cl). Mean scores and estimation were also computed for each component of CB and SF36 scales. A simple linear correlation was 
applied to explore the relationship between numerical demographic factors with CB and SF36 components. Mann-Whitney and Kruskal-Wallis tests were used to explore the relationship between mean scores of $\mathrm{CB}$ and SF36 components with categorical demographic factors. All statistical tests are two-sided and a p-value less than 0.05 is considered significant.

\section{ETHICAL CONSIDERATION}

Ethics approval was obtained from the Institutional Review Board in Ministry of Health. Written consent was obtained prior to participation.

\section{RESULTS}

Table I illustrates the demographic profile of the participants. A total of 32 caregivers participated in this study. The mean age of the participants is 42.3 years (15.3 years). Female and male participants are similar in number with the female participants (53.1\%) being slightly more than the male participants (46.9\%). A large proportion of the participants are Malay (84.4\%) with the rest being others (15.6\%). The mean education years of the participants are 13.8 years (5.4 years). The relationships of the participants with the patients include child (43.8\%), relative (18.8\%), spouse (15.6\%) and others (15.6\%).

Table II demonstrates the mean values of each component of the CB scale. The domain with the highest mean score $(\mathrm{SD})$ was general strain with a mean score of $1.8(0.7)$, followed by isolation with a mean score of 1.5 (0.5), disappointment with a mean score of 1.5 (0.5), environment with a mean score of $1.5(0.5)$ and emotional involvement with a mean score of $1.2(0.4)$.

Table III shows the mean values of the scales present in the RAND SF-36. The component with the highest mean score (SD) was physical functioning with a mean score of 84.4 (21.6), followed by emotion well-being with a mean score of 76.3 (16.4), social functioning with a mean score of 71.1 (21.6), and health change which had the lowest mean score of 57.8 (22.4).

Table IV demonstrates the correlation between various components of SF-36, CB scale and three demographic

Table I. Sociodemographic information of the caregivers $(n=32)$.

\begin{tabular}{|c|c|c|c|c|c|}
\hline Variable & $\mathbf{N}$ & (\%) & Mean & (SD) & (95\% Cl) \\
\hline Age & & & 42.3 & (15.3) & $(36.7,47.8)$ \\
\hline \multicolumn{6}{|l|}{ Gender } \\
\hline Male & 15 & $(46.9)$ & & & $(29.5,65.0)$ \\
\hline Female & 17 & $(53.1)$ & & & $(35.0,70.5)$ \\
\hline Income & & & 1349.8 & (1414.2) & $(840.0,1860.0)$ \\
\hline \multicolumn{6}{|l|}{ Ethnicity } \\
\hline Malay & 27 & $(84.4)$ & & & $(66.5,94.1)$ \\
\hline Others & 5 & $(15.6)$ & & & $(5.9,33.5)$ \\
\hline \multicolumn{6}{|l|}{ Religion } \\
\hline $\begin{array}{l}\text { Islam } \\
\text { Others }\end{array}$ & $\begin{array}{c}29 \\
3 \\
\end{array}$ & $\begin{array}{c}(90.6) \\
(9.4)\end{array}$ & & & $\begin{array}{c}(73.8,97.5) \\
(2.5,26.2)\end{array}$ \\
\hline $\begin{array}{l}\text { Education level } \\
\text { (years) }\end{array}$ & & & 13.8 & $(5.4)$ & $(11.8,15.8)$ \\
\hline \multicolumn{6}{|l|}{ Relationship } \\
\hline Child & 14 & $(43.8)$ & & & $(26.8,62.1)$ \\
\hline Spouse & 5 & $(15.6)$ & & & $(5.9,33.5)$ \\
\hline Parent & 2 & $(6.3)$ & & & $(1.1,22.2)$ \\
\hline Relative & 6 & (18.8) & & & $(7.9,37.0)$ \\
\hline Others & 5 & (15.6) & & & $(5.9,33.5)$ \\
\hline
\end{tabular}

$\mathrm{N}$ : frequency; SD: standard deviation; Cl: confidence interval.

Table II. Mean scores of caregiver burden domains $(n=32)$.

\begin{tabular}{|l|c|c|c|}
\hline & Mean & (SD) & $(95 \%$ CI) \\
\hline General strain & 1.8 & $(0.7)$ & $(1.5,2.0)$ \\
\hline Isolation & 1.5 & $(0.5)$ & $(1.3,1.7)$ \\
\hline Disappointment & 1.5 & $(0.5)$ & $(1.4,1.7)$ \\
\hline Environment & 1.5 & $(0.5)$ & $(1.1,1.3)$ \\
\hline Emotional involvement & 1.2 & $(0.4)$ & $(1.4,1.7)$ \\
\hline
\end{tabular}

Scoring (1: lowest; 4: highest). SD: standard deviation; Cl: confidence interval. 
variables which include age, income and education. In terms of correlation between CB scale and SF-36 scales, general strain had evidence of significant effects with several components of the scales of SF-36 including physical functioning $(r=-0.50)$, emotional well-being $(r=-0.40)$, pain $(r=-0.59)$ and health change $(r=-0.44)$. Isolation also had evidence of significant effects with the scales of SF-36 which including role limitations due to physical health $(r=-0.40)$, emotional well-being $(r=-0.49)$, general health $(r=-0.46)$ and health change $(r=-0.42)$. In addition to that, disappointment also had evidence of significant effects with some scales of the SF-36 including energy/fatigue $(r=-0.39)$, pain $(r=-0.52)$, and health change $(r=-0.44)$. Lastly, environment had evidence of significant effects with emotional well-being $(r=-0.44)$ and health change $(r=-0.37)$. In terms of the correlation between demographics and CB scale, age had evidence of low positive significant effects with general strain (0.35) where increased age was significantly associated with higher general strain.
Income had evidence of significant moderate effects with Isolation (0.54) where increased income was significantly associated with higher Isolation.

In terms of the correlation between demographics and SF-36 scales, age had evidence of significant moderate negative effects with physical functioning $(r-0.67)$ where it was observed that increased age was significantly associated with reduced physical functioning. Gender also demonstrates evidence of significant effects with health-related outcomes where male caregiver had higher role functioning score (mean $=68.3 \pm 46.7$ ) than females (mean $=50.0 \pm 40.5)(p=0.002)$. Males (mean $=68.9 \pm 42.7$ ) had higher emotional role functioning score than females (mean $=62.7 \pm 47.0)(p=<0.001)$. Females (mean $=71.3 \pm 22.0$ ) had higher social functioning score than males (mean $=70.8 \pm 22.0)(p<0.001)$. Females (mean $=66.5 \pm 12.7)$ had higher general health score than males (mean $=61.7 \pm 19.2)(p<0.001)$.

The mean (SD) physical functioning score of the various relations of caregivers to care receivers. It showed

Table III. Mean scores of RAND SF-36 components $(n=32)$.

\begin{tabular}{|l|c|c|c|}
\hline & Mean & (SD) & (95\% CI) \\
\hline Physical functioning & 84.4 & $(21.6)$ & $(76.6,92.2)$ \\
\hline Emotional well-being & 76.3 & $(16.4)$ & $(70.3,82.2)$ \\
\hline Social functioning & 71.1 & $(21.6)$ & $(63.3,78.9)$ \\
\hline Pain & 67.6 & $(22.9)$ & $(59.3,75.9)$ \\
\hline Energy/fatigue & 65.8 & $(16.3)$ & $(60.0,71.7)$ \\
\hline Emotional role functioning & 65.6 & $(44.4)$ & $(49.6,81.6)$ \\
\hline General health & 64.2 & $(16.0)$ & $(58.4,70.0)$ \\
\hline Physical role functioning & 58.6 & $(43.8)$ & $(42.8,74.4)$ \\
\hline Health change & 57.8 & $(22.4)$ & $(49.7,65.9)$ \\
\hline
\end{tabular}

Scoring (0 is lowest, 100 is highest); SD: standard deviation; Cl: confidence interval.

Table IV. Correlation between demographic variables and caregiver burden and SF-36 ( $n=32)$.

\begin{tabular}{|c|c|c|c|c|c|c|c|c|}
\hline & Age & Income & Education & $\begin{array}{l}\text { General } \\
\text { strain }\end{array}$ & Isolation & Disappointment & $\begin{array}{c}\text { Emotional } \\
\text { involvement }\end{array}$ & Environment \\
\hline General strain & 0.35 * & 0.34 & -0.09 & - & - & - & - & - \\
\hline Isolation & 0.32 & 0.54 * & 0.05 & - & - & - & - & - \\
\hline Disappointment & 0.11 & 0.13 & 0.03 & - & - & - & - & - \\
\hline Emotion & 0.08 & -0.05 & -0.03 & - & - & - & - & - \\
\hline Environment & -0.21 & 0.03 & 0.08 & - & - & - & - & - \\
\hline Physical functioning & $-0.67 *$ & -0.22 & 0.02 & -0.27 & -0.31 & -0.16 & 0.20 & 0.19 \\
\hline $\begin{array}{l}\text { Physical role } \\
\text { functioning }\end{array}$ & -0.24 & -0.16 & 0.04 & -0.31 & $-0.40 *$ & -0.28 & 0.24 & -0.23 \\
\hline $\begin{array}{l}\text { Emotional role } \\
\text { functioning }\end{array}$ & -0.09 & -0.04 & -0.12 & -0.19 & -0.20 & -0.34 & 0.31 & -0.06 \\
\hline Energy/fatigue & -0.27 & -0.07 & -0.20 & -0.50 * & -0.32 & -0.39 * & 0.04 & -0.32 \\
\hline Emotional well-being & -0.05 & -0.20 & -0.004 & -0.40 * & $-0.49 *$ & -0.23 & -0.20 & -0.44 * \\
\hline Social functioning & -0.26 & -0.01 & 0.15 & -0.30 & -0.31 & -0.31 & 0.13 & -0.17 \\
\hline Pain & -0.06 & -0.16 & 0.06 & $-0.59 *$ & -0.09 & $-0.52^{*}$ & 0.01 & -0.28 \\
\hline General health & -0.33 & $-0.40 *$ & -0.04 & $-0.37^{\star}$ & -0.46 * & -0.38 * & 0.02 & -0.13 \\
\hline Health change & -0.09 & -0.03 & -0.13 & $-0.44^{\star}$ & $-0.42^{*}$ & -0.44 * & 0.19 & $-0.37^{*}$ \\
\hline
\end{tabular}


that there was a significant difference in terms of the physical functioning score between all the relationships $(p=0.026)$. The mean $(S D)$ role limitations due to physical health score of the various relations of caregivers to care receivers were $53.6 \pm 45.8$ for 'child', $10.0 \pm 22.4$ for 'spouse', $100.0 \pm 0.0$ for 'parent', $75.0 \pm 31.6$ for 'relative', and $85.0 \pm 33.5$ for 'others'. It showed that there was an evidence of significant effects in terms of role limitations due to physical health score between all the relationships $(p=0.028)$.

\section{DISCUSSION}

To the best of our knowledge, this is the first study exploring dimensions of caregiver burden and its relationship towards health-related quality of life in Brunei. Firstly, all components of caregiver burden except for emotional involvement had evidence of significant effects with some aspects of health-related quality of life. These effects demonstrated that increase in caregiver burden were associated with decreased health-related quality of life. This corroborated with a Japanese study where stroke caregivers has been shown to have higher burden and lower health-related quality of life ${ }^{10}$. Another study in the United Kingdom demonstrated that there was evidence of low but significant effects between burden and quality of life of caregivers ${ }^{11}$. Similarly, another study that was done in Hong Kong showed that all domains related to quality of life were negatively affected by caregiver burden, with partial correlations ranging from 0.2 to $0.4^{12}$. In addition to that, the findings also showed that social functioning was not affected by the caregiver burden. However, the same Japanese study demonstrated that increased burden was associated with lower social functioning although this was relatively higher than what is experienced by caregivers from other countries ${ }^{10}$.

Secondly, the results demonstrated that only age had significant correlations with some aspects of caregiver burden and quality of life. This is supported by a study where it was shown that age explained more of the variation in physical burden ${ }^{10}$. Another study also showed that age was one of the significant predictors of decreased physical functioning score ${ }^{13}$. Income, on the other hand, did not show any significant correlations with any domains of health-related quality of life. This could be due to Bruneians receiving various financial aids from the government and health care centres including free health care, old age pension, free loans for some medical equipment such wheelchairs, hospital beds, suctions, and more, and financial support from Jabatan Pembangunan Masyarakat (JAPEM) and Brunei Islamic Religious Council (MUIB) for those who are underprivileged. These benefits are unique to Bruneians and are not found in other parts of the world.

Finally, in terms of implication to practice, health care professionals in the community setting should carry out more formal assessments of caregiver burden especially for those who are at risk of higher burden. Screening tools can be used to identify those who are at risk of having high caregiver burden and more in-depth assessments can be carried out for these individuals. Community care services such as respite care and support groups should be developed to further aid the care of patients with long term conditions to alleviate caregiver burden. Furthermore, training courses should also be offered to the caregivers so that they can be better equipped and more prepared to take care of the care recipients.

\section{LIMITATIONS}

Small sample size limits generalisability of findings to caregiver population in Brunei. Use of non-parametric analysis may lead to type 1 and type 2 errors. The cross-sectional nature of this study does not have causal inferences. Future studies should consider assessing other sociodemographic variables that could affect caregiver burden and health-related quality of life such as the sociodemographic variables of the care recipient. More detailed qualitative studies should be done to provide a better insight on caregiver burden.

\section{CONCLUSIONS}

In summary, caregiver burden does have significant associations with health-related quality of life. Certain demographic factors such as age, income and gender showed associations with caregiver burden and healthrelated quality of life. Significant relationship between caregiver burden and health-related quality of life suggested importance of recognising and raising awareness of this burden among caregivers within Brunei's community. Without any intervention, these caregivers may suffer from worsening health-related quality of life. Therefore, it is recommended that relevant authorities prioritise caregiver burden as a potential issue for optimal care of patients and carers.

\section{Acknowledgements}

We thank Sarinah Haji Md Yassin, BSc (Hons) for assistance with the data collection period. We also express our utmost sincere appreciation to all participations who have contributed significantly to this study.

\section{References}

1 Sullivan AB, Miller D. Who is taking care of the 
caregiver? J Patient Exp 2015;2:7-12. https://doi. org/10.1177/237437431500200103

2 Zarit S, Todd P, Zarit J. Subjective burdens of husbands and wives as caregivers: a longitudinal study. Alzheimer Dis Assoc Disord 1987;1:109-10. https://doi. org/10.1097/00002093-198701020-00026

3 Etters L, Goodall D, Harrison BE. Caregiver burden among dementia patient caregivers: a review of the literature. J Am Acad Nurse Pract 2008;20:423-8. https://doi. org/10.1111/j.1745-7599.2008.00342.x

4 Leroi I, McDonald K, Pantula H, et al. Cognitive impairment in parkinson disease: Impact on quality of life, disability, and caregiver burden. J Geriatr Psychiatry Neurol 2012;25:20814. https://doi.org/10.1177/0891988712464823

5 Adelman RD, Tmanova LL, Delgado D, et al. Caregiver burden: a clinical review. JAMA 2014;311:1052-9. https://doi. org/10.1001/jama.2014.304

6 Baronet A-M. Factors associated with caregiver burden in mental illness: a critical review of the research literature. Clin Psychol Rev 1999;19:819-41. https://doi.org/10.1016/ S0272-7358(98)00076-2

7 Rigby H, Gubitz G, Phillips S. A systematic review of caregiver burden following stroke. Int J Stroke 2009;4:28592. https://doi.org/10.1111/j.1747-4949.2009.00289.x
8 S. E, B. M, L. A. Caregiver's burden of patients 3 years after stroke assessed by a novel caregiver burden scale. Arch Phys Med Rehabil 1996;77:177-82. https://doi. org/10.1016/S0003-9993(96)90164

9 Ware JE, Sherbourne CD. The MOS 36-Item Short-Form Health Survey (SF-36). Med Care 2006;30:473-83. https:// doi.org/10.1097/00005650-199206000-00002

10 Morımoto T, Schreıner AS, Asano H. Caregiver burden and health-related quality of life among stroke caregivers. Age Ageing 2003;32:218-23.

11 McCullagh E, Brigstocke G, Donaldson N, et al. Determinants of caregiving burden and quality of life in caregivers of stroke patients. Stroke 2005;36:2181-6. https://doi. org/10.1161/01.STR.0000181755.23914.53

12 Ho SC, Chan A, Woo J, et al. Impact of caregiving on health and quality of life: a comparative population-based study of caregivers for elderly persons and noncaregivers. Journals Gerontol - Ser A Biol Sci Med Sci 2009;64:873-9. https://doi.org/10.1093/gerona/glp034

13 Hughes SL, Giobbie-Hurder A, Weaver FM, et al. Relationship between caregiver burden and health-related quality of life. Gerontologist 1999;39:534-45. https://doi. org/10.1093/geront/39.5.534 